\section{First Experiences with Stark Effect Microwave Fourier Transform Spectroseopy}

\section{G. Bestmann and H. Dreizler}

Abteilung Chemische Physik im Institut für Physikalische Chemie der Universität Kiel

Z. Naturforsch. 37a, 615-616 (1982);

received March 31, 1982

Measurements of the Stark effect by MWFT spectroscopy were not made up to now. We tested a modification of our spectrometer, which allows these measurements and opens this field also for MWFT spectroscopy.

In a series of publications $[1-6]$ we demonstrated that microwave Fourier transform (MWFT) spectroscopy is a useful tool for the investigation of fine structures in rotational spectra of molecular gases at low pressures in thermodynamic epuilibrium.

MWFT spectroscopy has several advantages compared to conventional Stark spectroscopy as e.g. modulation and power broadening are absent. Up to now it was not possible to observe the Stark effect as a waveguide cell without Stark septum was used.

As the Stark effect is very helpful for the assignment of microwave spectra and for the determination of dipole moments, we equipped our MWFT spectrometer [6] with a X-band Stark cell of conventional construction. MWFT spectroscopy is very sensitive to perturbations produced by reflections of the polarizing microwave pulse. Nevertheless we observed the Stark effect of carbonylsulfide, OCS, and sulfurdioxide, $\mathrm{SO}_{2}$, without perturbations. We think the reflected pulses at the ends of the Stark septum are absorbed quickly by the waveguide isolators which are located about $10 \mathrm{~cm}$ from the ends of the septum. From our experiences with oversized sample cells we think that it is necessary to use a Stark cell with a waveguide of the nominal band.

Figure 1 gives the Stark effect of the $J=0-1$ transition of OCS with a de Stark field of approximately $600 \mathrm{~V} / \mathrm{cm}$. Unfortunately the Stark septum is displaced about $0.1 \mathrm{~mm}$ out of the center of the waveguide. So the Stark satellites split into two components due to the different electric fields on both sides of the septum. The field free transition

Reprint requests to Prof. Dr. H. Dreizler, Abt. Chemische Physik, Institut für Physikalische Chemie, Universität Kiel, Olshausenstraße 40-60, D-2300 Kiel.

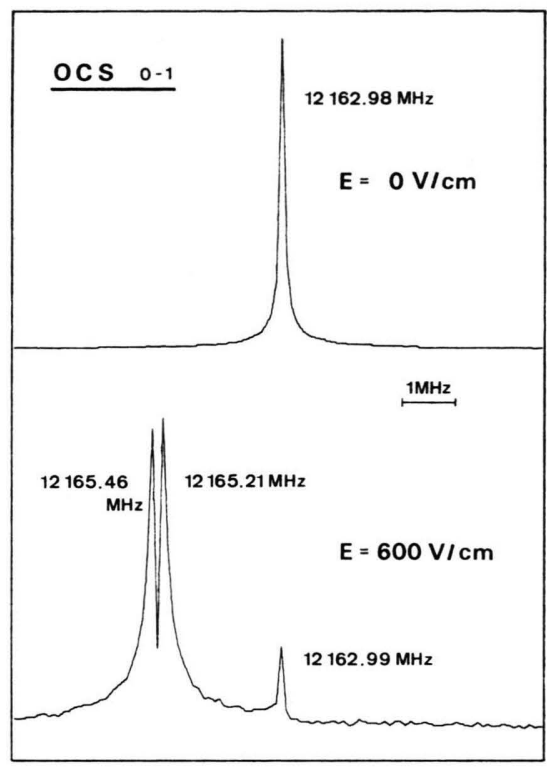

Fig. 1. Stark effect of the transition $J=0-1$ of OCS. A range of $10 \mathrm{MHz}$ out of a $50 \mathrm{MHz}$ scan is shown. Data acquisition: $10 \mathrm{~ns}$ sample interval, 1024 data points, time domain averaging $2^{16}$ cycles, $T=295 \mathrm{~K}, p=2$ mTorr, polarizing microwave at $12162 \mathrm{MHz}$. (The splitting of the transition is discussed in the text.)

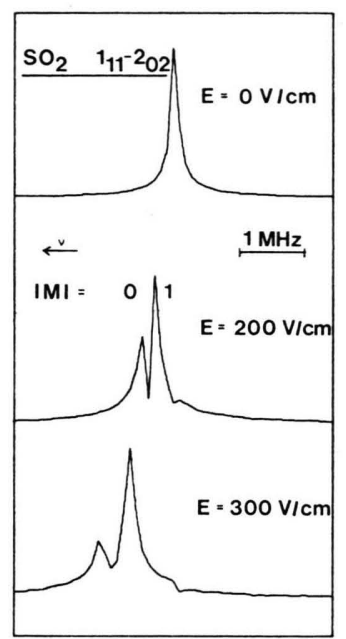

Fig. 2. Stark effect of the transition $J=1_{11}-2_{02}$ of $\mathrm{SO}_{2}$. Theoretical relative intensities of the Stark components $I(M=0)=4, I(M=1)=6$. A range of $5 \mathrm{MHz}$ out of a $50 \mathrm{MHz}$ scan is shown. Data acquisition: see Figure 1. Polarizing microwave at $12256 \mathrm{MHz}$. Transition frequency $(E=0 \mathrm{~V} / \mathrm{cm}): 12256.59 \mathrm{MHz} ;(E=200 \mathrm{~V} / \mathrm{cm})$ : $M=0 \quad 12257.12 \mathrm{MHz}, \quad M=1 \quad 12256.87 \mathrm{MHz} ; \quad(E=300$ $\mathrm{V} / \mathrm{cm}): M=012257.76 \mathrm{MHz}, M=112257.29 \mathrm{MHz}$. 
can still be seen in the pattern because the septum is somewhat shorter than the sample cell.

Figure 2 demonstrates the Stark effect of the transition $J=1_{11}-2_{02}$ of $\mathrm{SO}_{2}$ with a de field of approximately 200 and $300 \mathrm{~V} / \mathrm{cm}$. The patterns do not give the correct intensities. This is still a difficulty in MWFT spectroscopy.

[1] E. Fliege, G. Bestmann, R. Schwarz, and H. Dreizler, Z. Naturforsch. 36a, 1124 (1981)

[2] E. Fliege, H. Dreizler, and U. Andresen, Z. Naturforsch. 36 a, 1122 (1981).

[3] E. Fliege, G. Bestmann, M. Andolfatto, and H. Dreizler, Z. Naturforsch. 36a, 1126 (1981).
We hope to improve our setup by a more precise Stark cell in order to obtain more reliable results for Stark split rotational transition in particular for high $J$ quantum numbers.

We thank the members of our group for many discussions and the Deutsche Forschungsgemeinschaft and Fonds der Chemie for funds.

[4] H. Dreizler and F. Scappini, Z. Naturforsch. 36a, 1187 (1981).

[5] F. Scappini and H. Dreizler, Z. Naturforsch. 36a 1327 (1981).

[6] G. Bestmann and H. Dreizler, Z. Naturforsch. 37 a, 58 (1982). 